\title{
CONSTRUCCIÓN DE UNA IDENTIDAD NACIONAL: EL DISCURSO HISTORIOGRÁFICO DE VENEZUELA EN EL SIGLO XIX
}

\author{
POR \\ NIKITA HARWICH VALLENILLA \\ (Instituto de Investigaciones Históricas. \\ Universidad Católica Andrés Bello, Caracas)
}

A raíz de las guerras de Independencia y del desmembramiento, en 1830, de la Gran Colombia bolivariana, la elaboración de una historia nacional venezolana tiene de antemano que enfrentar un doble problema: justificar, por una parte, la ruptura de los vínculos seculares con la monarquía española; y justificar, además, la ruptura del proyecto unitario ideado por Bolívar. "Que ignore el ciudadano la historia de su Patria no es compatible, ni con la civilización, ni con el patriotismo», advierte un aviso publicado en el diario caraqueño El Venezolano en septiembre de 1840 (1). Conviene no solamente informar, sino formar a este nuevo ciudadano:

Los verdaderos republicanos deben aleccionarse con la historia, porque sólo siendo ilustrados y virtuosos podrán ser verdaderos patriotas, laborando por lograr el prestigio y la soberanía de las instituciones democráticas, encaminadas a realizar el hermoso ideal de libertad, aspiración nobilísima de nuestros insignes libertadores.

proclama un manual escolar publicado en 1858 (2). Historia, ilustración, virtud: santa trinidad de una novedosa moral cívica.

(1) El Venezolano, Caracas, lunes 7 de septiembre de 1840.

(2) Juan Esté, Lecciones primarias de la Historia de Venezuela dispuestas para los niños Caracas: Imprenta de Tomás Antero, 1858, págs. 1-11. 
Sin embargo, el problema más urgente en un primer momento es el de precisar las bases territoriales de una nacionalidad que es aún difícil de definir de otra manera:

el levantamiento de planos, formación de itinerarios y cuadros estadísticos del Estado, es una empresa de primera importancia para Venezuela, cuyos útiles efectos serán trascendentales a la mejor dirección de las operaciones militares, al conocimiento de los límites de las provincias, a la exactitud en el establecimiento de las contribuciones y al fomento de la agricultura, porque facilita la apertura y mejora de los caminos, el desagüe de los lagos y pantanos y la limpieza y navegación de los ríos (3).

Con base en estos considerandos, el Congreso Constituyente, que todavía se encuentra provisionalmente reunido en Valencia, aprueba el 13 de octubre de 1830 un decreto encargando al Poder Ejecutivo de "comisionar un oficial facultativo para la formación de planos de las provincias de Venezuela fue reúnan noticias de geografía física y estadística», trabajo que deberá concluirse en un plazo, considerado como "suficiente», de tres años (4).

Era claro el objetivo: el proyecto político de la nueva república debía acompañarse de un censo, tan completo como fuese posible, de sus recursos. Por otra parte, la necesidad de negociar un trazado de fronteras con los Estados vecinos hacía imperativo un conocimiento de los límites geográficos por reivindicar. Así Venezuela estaría también en condiciones de legitimar plenamente su soberanía y de ser admitida como actor en derecho propio dentro del llamado "concierto de naciones".

El comisionado encargado de llevar a cabo la tarea fijada por el Congreso de Valencia sería el oficial de origen italiano. Agustín Codazzi (1793-1859), un ex-corsario quien se había pasado al servicio de la Gran Colombia y cuyas competencias habían sido debidamente apreciadas por José Antonio Páez, el caudillo supremo de la joven república venezolana.

Es, por lo tanto, al través de la geografía donde buscará definirse una identidad, cuyas referencias históricas distan mucho de suscitar una valoración unánime. Para las élites que tienen ahora en sus manos los destinos futuros del país, la pregunta queda planteada: no se quiere ya ser español o colombiano, pero

(3) Citado en: Mario Briceño Iragorry, Pasión y triunfo de dos grandes libros Caracas, 1961, pág. 8.

(4) Ibíd. 
¿Cómo ser venezolano? En otras palabras, ¿cómo podrá compaginarse el rechazo de un pasado inmediato, o a lo sumo reciente, con un discurso historiográfico a la vez consensual y que refleje el desarrollo real de los hechos? No deja de ser significativo que las dos primeras «historias nacionales» escritas en Venezuela después de 1830 -la de Feliciano Montenegro Colón y la de Rafael María Baralt - hayan sido concebidas como los apéndices de unas obras de geografía o de estadística.

El universo de este discurso historiográfico venezolano se elabora a partir de cuatro niveles de percepción. En primer lugar, el de las compilaciones documentales. Será sólo a partir de 1821, una vez consolidada la independencia, cuando se puede presenciar un esfuerzo sistemático para recuperar la memoria colectiva de los acontecimientos que han llevado a la creación de la nueva república la Gran Colombia en este caso. En 1826, Francisco Javier Yanes y Cristóbal L. Mendoza se dedican a la tarea de recopilar y editar una primera colección de Documentos relativos a la vida pública del Libertador de Colombia y del Perú, Simón Bolivar, para servir a la historia de la independencia de Suramérica. El propio Bolívar se encargó de proporcionar una buena parte de esta documentación. De los 22 tomos previstos, solo 15 alcanzaron a ser publicados antes de la muerte de Mendoza, ocurrida en febrero de 1829 y le tocaría entonces a Yanes proseguir sólo con el proyecto hasta su conclusión en 1833. Mientras tanto, uno de los antiguos edecanes del Libertador, Daniel Florencio O'Leary (1801-1854), retirado por entonces en Jamaica, se abocaba a una tarea similar con base en el fondo de archivo que tenía en su poder. Sin embargo, la publicación de esta segunda colección no se llevaría a cabo sino unos treinta años después de la muerte de O'Leary, entre 1875 y 1888. Finalmente, un tercer proyecto de recopilación histórica, iniciado en 1855 por Ramón Azpurúa y José Felix Blanco, se proponía completar la colección Yanes y Mendoza con documentos provenientes de varios países de América Latina y que cubrían, además, algunos aspectos del período colonial. Pero sería bajo el título genérico de Documentos para la vida pública del Libertador de Colombia, Perú y Bolivia que esta última empresa saldría a la luz pública, bajo la forma de 14 tomos publicados entre 1875 y 1878 .

Una primera observación se impone: la compilación hecha por Yanes y Mendoza será la única efectivamente disponible y utilizada por los autores de la "primera generación» de obras que conformaron el corpus historiográfico venezolano del siglo XIX. 
En el segundo nivel de percepción: Este corpus se abre en 1837 con el cuarto tomo de una Geografía general para el uso de la juventud, dedicado a la historia de Venezuela desde 1492 hasta la «Revolución de las Reformas» de 1835-1836. Su autor es Feliciano Montenegro y Colón (1781-1853), un antiguo oficial ahora convertido en educador.

Francisco Javier Yanes, por su parte, utilizará la masa de archivos que contribuyó a editar y publicar para redactar su propio Compendio de la Historia de Venezuela. Desde su descubrimiento y conquista hasta que se declaró Estado Independiente que sale de la imprenta en 1840. Yanes será también el autor de un segundo trabajo: la Relación documentada de los principales sucesos ocurridos en Venezuela desde que se declaró Estado Independiente hasta 1821. La Relación debía ser el complemento del Compendio. Pero, muy probablemente con miras a obviar unas inevitables polémicas, Yanes prefirió, por disposición testamentaria, demorar la publicación de este último libro hasta diez años después de su muerte, acaecida en 1842. Aunque el manuscrito de la Relación no llegó a ser publicado por primera vez sino en 1943, había sido ya ampliamente utilizado. El propio Yanes comunicó largos extractos de la obra, tanto a Montenegro y Colón como a Rafael María Baralt (1810-1860) quien supervisó la publicación en París, en 1841, de los tres tomos de su Resumen de la Historia de Venezuela, comisionado por el gobierno venezolano como complemento a la Geografía de Agustín Codazzi.

Las obras de Yanes, de Montenegro y de Baralt servirian, a su vez, de referencia para el Bosquejo de la historia militar de Venezuela de José de Austria (1791-1863), publicado en 1855, el cual en realidad sólo cubre el período de las guerras de Independencia; y para la Vida y Correspondencia del Libertador Simón Bolivar de Felipe Larrazábal (1816-1873), la primera biografía de Bolivar escrita por un autor venezolano y publicada originalmente en Nueva York en 1865. Finalmente, para cerrar esta lista de los "primeros historiadores venezolanos del siglo XIX", conviene mencionar los escritos de Juan Vicente González (1810-1866), los cuales fueron, en su mayoria, publicados bajo la forma de artículos de prensa entre 1848 y 1866 . Brillante panfletario más que historiador, González no dejó de ejercer una profunda influencia sobre el público de su época. Sus evocaciones biográficas, que no pretendían ocultar la pasión partidista de su autor, reflejaban también las orientaciones de una historia concebida como escuela de formación patriótica. 
Exceptuando a Larrazábal y a González, todos los demás autores participaron directamente en los acontecimientos de la independencia. Algunos, como Francisco Javier Yanes, hasta fueron actores de primerísimo plano. Pero para todos, el recurrir a la documentación disponible no representaba sino el complemento de un testimonio, muchas veces personal, sobre los acontecimientos y sus protagonistas. $Y$ todos, de una manera u otra, tuvieron que plantearse, asi fuera inconscientemente, el problema de los orígenes de una identidad nacional de la cual se harian los demiurgos.

A partir de este corpus, un tercer nivel de percepción del discurso historiográfico es el de una pedagogía cívica cuya expresión privilegiada será la de los manuales escolares. Sin embargo, en Venezuela, al igual que en los demás países de América Latina, la enseñanza obligatoria de una historia nacional sólo quedó establecida en las últimas décadas del siglo XIX. Además, tomando en cuenta las tasas ínfimas de escolaridad, los alcances de esta enseñanza no dejaban de ser muy limitados con respecto al conjunto de la población.

La verdadera difusión pedagógica de esta «historia patria» se llevaría a cabo a partir de las manifestaciones populares de acción cívica. Las inauguraciones de estatuas o de monumentos públicos, las celebraciones conmemorativas de determinadas fechas, así como el entierro de alguna personalidad, además de servir como pretexto para un elaborado ceremonial, se encargarían también de transmitir un mensaje histórico que repetía fielmente la lección que sólo algunos aprendían en las aulas de clase. El discurso de orden pasaba a ser entonces la pieza maestra de estas innumerables Apoteósis y Coronas fúnebres. Su objeto era edificar, fijar imágenes con la autoridad que pudiera conferirle las dotes de orador de quien lo pronunciaba. La historia - un cierto tipo de historia- traspasaba así el umbral de la vida cotidiana.

\section{II}

Dejando a un lado el caso de las compilaciones documentales, donde el recurso a una ayuda oficial, nada más para cubrir los costos de impresión, se hacía imprescindible, cabe notar que las dos primeras obras del corpus historiográfico venezolano también contaron con un patrocinio oficial. A la vez fundador en 1836 y 
director del primer colegio privado de secundaria inaugurado en Caracas después de la independencia -y que, por lo demás, se llamaba «Colegio de la Independencia» - Feliciano Montenegro y Colón podía enorgullecerse por el hecho de que entre sus alumnos figuraban los hijos del presidente Páez. Su proyecto de dedicarle un cuarto tomo de su Geografía general a la historia de Venezuela se justificaba, según sus propias palabras:

para oponer la verdad de mi relato a la multitud de falsedades con que el español D. Mariano Torrente ha querido lastimar la conducta de los americanos, siempre imbéciles a su modo de pensar y sanguinarios y malvados, como maliciosa y pérfidamente ha asegurado en su historia sobre las revoluciones de este Nuevo Mundo (5).

Por su parte, Agustín Codazzi no había podido terminar sus levantamientos cartográficos y estadísticos dentro del plazo fijado. Después de haber obtenido varias prórrogas, le proponía en 1839 al Congreso venezolano completar el trabajo que se le había confiado con una sección histórica «útil por las noticias que encierre y estimable por la moderación y exactitud en narrar los hechos». Pero, como explicaba entonces Codazzi:

[...] el conocimiento que tengo del idioma [castellano] no alcanza para escribirla con la corrección necesaria. Y ahí que me fue preciso buscar un colaborador capaz de llevar cumplidamente a efecto lo que yo no podía hacer (6).

El colaborador aludido por Codazzi era Rafael María Baralt, un joven oficial de artillería nacido en Maracaibo, quien había participado en las operaciones militares - por lo demás reducidas- que sancionaron la secesión de Venezuela en 1830 y quien se había incorporado desde 1832 como miembro de la influyente Sociedad de Amigos del País de Caracas, cuyo Anuario tenía a su cargo redactar (7).

Por coincidencia, los autores de estas primeras «historias oficiales" resultaban ser ambos militares de carrera. De ahí que su empeño en representar la secuencia de acontecimientos conside-

(5) Feliciano Montenegro y Colón, Historia de Venezuela Caracas: Academia Nacional de la Historia, 1960, Tomo 1, págs. 91-92.

(6) Agustín Codazzi, "Prólogo al Atlas físico y político de Venezuela" en: Obras Escogidas Caracas: Biblioteca Venezolana de Cultura, 1960, Tomo II, págs. 6-7.

(7) Véase: Agustín Millares Carlo, Rafael Maria Baralt, 1810-1860, Caracas, Universidad Central de Venezuela, 1960. 
rada, apoyándose hasta donde fuera menester en la documentación disponible para entonces, se traduciria por una inclinación a privilegiar el aspecto puramente militar del relato -campañas, batallas, maniobras - y a dedicarle la mayor parte de sus respectivas obras al período de las guerras de Independencia comprendido entre 1810 y 1825 . En un mismo orden de ideas, la colonización española se presentaría casi exclusivamente como una empresa de reducción y de sometimiento de los indígenas cuya presencia sólo tomaba la forma de una resistencia guerrera ante los intentos de ocupación del territorio. Baralt no vacilaba en afirmar que

Los trabajos de la paz no dan materia para la historia; cesa el interés que ésta inspira cuando no puede referir grandes crímenes, sangrientas batallas o calamitosos sucesos (8).

Esta frase, muchas veces reproducida, no basta sin embargo para calificar -o descalificar, según el punto de vista adoptadoel contenido de estos primeros intentos por redactar una historia nacional. En efecto, Montenegro y Baralt no se habían limitado solamente a hacer un recuento impersonal de "sangrientas batallas» o de "grandes crímenes». Para Baralt

[...] El ejemplo de América es una dolorosa muestra de lo que influyen en el carácter de un pueblo las circunstancias que lo rodean, el gobierno que lo dirige, la civilización que ha alcanzado. La España en tiempo de la conquista acababa de salir de aquel estado bárbaro a que redujo a la Europa la antigua lucha de los reyes, de los nobles, del clero, y de las comunidades [...] Hoy mismo, al cabo de tres siglos de progresos más o menos rápidos en el antiguo mundo, ninguna de sus naciones ha llegado a ese estado perfecto de civilización. Pues ¿cómo se quiere que la España lo hubiese alcanzado entonces, por que fuese entre todas ellas la más fuerte y poderosa? (9).

Sin tratar de minimizar los excesos de la conquista y de la colonización, Baralt, en su Resumen de la Historia de Venezuela, buscaba presentar una visión equilibrada de las cosas, así como evaluar y reconocer lo que, dentro del "carácter nacional" venezolano era una herencia directa de España. Una misma preocu-

(8) Rafael María BARALt, Resumen de la Historia de Venezuela Bruges-Paris, Desclée de Brouwer, 1939, Tomo III, pág. 144.

(9) Ídem, Tomo I, pág. 135. 
pación de equidad se podía encontrar también en el relato de los acontecimientos de la independencia y del largo período de guerras que se desarrolló en esa oportunidad. Baralt, quizás inconscientemente, reproducía por lo demás un doble discurso político: a la vez el de la tradición - un discurso de fidelidad- y el de la modernidad. Conceptos tales como "nación", "patria", «república», "pueblow o klibertad» aparecen utilizados en unos contextos muy distintos dentro de la misma obra, según se refieren al período colonial o a las décadas posteriores, contribuyendo así a crear una suerte de equívoco en la mente de un lector desprevenido (10).

Montenegro y Colón, por su parte, siempre estableció en su relato una distinción entre aquellos ejércitos investidos de una legitimidad oficial -así fuesen españoles o «patriotas»- y los jefes armados de tropas irregulares - de uno $u$ otro bandocuyos excesos eran denunciados en igualdad de términos con la imparcialidad que podía conferir un juicio moral sobre los horrores de la guerra.

Al escribir sus respectivas obras, ambos autores tomaban el riesgo de enfrentarse a un conjunto de orientaciones contradictorias. ¿Cómo presentar favorablemente la personalidad y la acción de Bolívar y justificar, al mismo tiempo, la necesidad de romper la unión grancolombiana? ¿Cómo, en otras palabras, conciliarse las susceptibilidades de actores políticos quienes, en su mayoría, se encontraban ahora a la cabeza del nuevo Estado?

Cuando salió publicado, el primer tomo del Resumen de Rafael María Baralt -el que trataba de la conquista y del período colonial - fue objeto de comentarios elogiosos por parte de dos miembros de la Sociedad Geográfica de París: Sabin Berthelot, su Secretario General y Henri Terneaux. Para Berthelot, no cabía la menor duda que la obra era una feliz expresión de «identidad nacional» (11), mientras que Terneaux declaraba enfáticamente:

[...] nunca hemos visto las causas de la decadencia interior de España explicadas de una manera más clara y más concisa;

y, al mismo tiempo, recomendaba al gobierno venezolano que

(10) Véase: Elena Plaza, "Historiografía y nacionalidad: el 'Resumen de la historia de Venezuela' de Rafael María Baralt", Tiempo y Espacio, Caracas 1990, Vol. VII, $n^{Q} 13$, págs. 63-78.

(11) "Análisis del primer volumen de la Historia de Venezuela hecho por M. S. Berthelot, Secretario General de la Sociedad Geográfica de París", El Venezolano, Caracas, 7 de agosto, $n^{9} 61,1841$. 
tradujera la obra en francés, "de tal manera que pudiese ser conocida en toda Europan (12). En Venezuela, por el contrario, las reacciones habrían de ser muy distintas.

Un silencio casi unánime acogió la salida en Caracas de la Geografía general de Montenegro y Colón, sobre todo cuando fue publicado, en 1837, el tomo cuarto dedicado a la historia del país. Sólo un artículo anónimo, publicado en agosto de 1838 en las columnas de El Nacional, aportó algunas correcciones de detalle a la presentación que hacía el autor de un episodio menor de la guerra de independencia (13). Hecho elocuente: a fines del año 1841, más de 1.600 ejemplares de la obra todavía se encontraban depositados - "secuestrados" escribiria luego Montenegro- en los almacenes del Tesoro Público (14). Bien puede pensarse que se trataba aquí de la casi totalidad de la edición original.

Sin lugar a dudas que Montenegro había sido víctima de su pasado. Ciertamente, había participado en los combates de la guerra de independencia, pero en las filas del cuerpo expedicionario español y, a pesar de haberse identificado en la península con la causa liberal, seguia siendo considerado como un traidor por la mayoria de sus compatriotas venezolanos y hasta su muerte tuvo que defenderse de la acusación que le fuera hecha de haber sustraído documentos confidenciales de la Secretaría de Defensa cuando resolvió regresar a España en julio de 1811. ¿Cómo otorgarle autoridad alguna para escribir la historia de un país el cual había combatido? No podía sino quedar descalificado de antemano.

El Resumen de Baralt también suscitó una reacción negativa. $\mathrm{Su}$ relato de la conquista fue denunciado como demasiado favorable a los españoles. ¿Cómo pretender atribuir el calificativo de heroicas a «las acciones más bárbaras que recuerda la historia» (15)? Por otra parte el relato "equilibrado» de las campañas militares de la independencia y para el cual Baralt se había

(12) "Juicio de Mr. H. Terneaux sobre la Historia Antigua de Venezuela del Sr. R. M. Baralt", El Venezolano, $\mathrm{n}^{0}$ 61, Caracas, 7 de agosto, $\mathrm{n}^{9} 61,1841$.

(13) "Apuntes sobre la guerra de la independencia", El Nacional, 1838, n" 124, Caracas, 12 de agosto. Véase también: Napoleón Franceschi, "Don Feliciano Montenegro y Colón y su aporte historiográfico", trabaje presentado en el Seminario "La creación de la Nación. Historia e historiadores en el siglo XIX: el caso de Venezuela" Caracas, Universidad católica Andrés Bello, octubre de 1990.

(14) Feliciano MONTENEGRo y COLÓN, Recuerdos históricos y curiosidades útiles, Caracas, Imprenta de Simón Camacho, 1847, pág. 22

(15) Fermín TORo, "El Resumen de la Historia de Venezuela de Rafael María Baralt", El Liceo Venezolano, Caracas, enero, $\mathrm{n}^{9} 1,1842$. 
inspirado en parte del texto de Montenegro, como bien lo ha demostrado Antonio Mieres (16) no respondía a lo que esperaban los lectores. Duramente afectado por una crítica que consideraba tan injusta como desprovista de fundamento, Baralt se ausentó definitivamente de Venezuela en septiembre de 1841 para instalarse, luego, en España donde murió. De los 3.000 ejemplares que conformaron la edición original del Resumen, solamente 1.000 aparecían como vendidos en mayo de 1845 . Codazzi, quien debía reembolsarle al Estado venezolano los adelantos percibidos con la venta de las colecciones, tuvo que enfrentarse a toda clase de dificultades hasta lograr intercambiar su deuda por la entrega de los ejemplares sin vender (17).

Las mismas reservas para con las obras de Montenegro y de Baralt se manifestaron también con la publicación de los demás textos del corpus historiográfico venezolano del siglo XIX. El Compendio de Francisco Javier Yanes no suscitó comentario alguno la prensa de lo época, salvo toda una serie de pequeños avisos - probablemente mandados publicar por el propio impresor del libro- que recomendaban su difusión en los colegios (18). Yanes, sin embargo, ostentaba un curriculum dificilmente cuestionable. Como miembro del Congreso Constituyente de 1811, había sido uno de los firmantes de la Declaración de Independencia y desempeñó, pocos años después, altas funciones judiciales dentro del marco de la república grancolombiana de la cual era uno de los líderes civiles más respetados.

Puede suponerse que el Compendio también fue considerado demasiado favorable a España y que no reflejaba de una manera lo suficientemente convincente la versión inequívoca de una "leyenda negra". "Cuando una colonia establecida en un país distante, rico y fértil llega al estado de componerse de hombres laboriosos, inteligentes y acaudalados, su emancipación en un acontecimiento inevitablen, afirmaba Yanes al explicar las causas que habían llevado a Venezuela a proclamar su independencia (19). Semejante cuadro no correspondía a la imagen de tres siglos de opresión y de oscurantismo que era menester traer a

(16) Véase: Antonio Mieres. Tres autores en la historia de Baralt. Caracas: Universidad Central de Venezuela, 1966, passim.

(17) Véase Briceño, [3], op. cit., págs. 32 y ss., PlazA, [10], págs. 78-92.

(18) Por ejemplo en El Liberal Caracas, 19 de mayo de 1840, n² 212.

(19) Francisco Javier YANES, Compendio de la Historia de Venezuela desde su Descubrimiento y Conquista hasta que se declaró Estado Independiente. Caracas: Academia Nacional de la Historia, 1944, pág. 105. 
colación. Pero tomando en cuenta los méritos del autor, más valía el silencio que el inicio de una polémica.

Estrictamente limitado a una crónica de las campañas militares de la independencia, el Bosquejo de José de Austria no presentaba mayor problema en cuanto a una interpretación de la historia y, por ende, tampoco aportaba elementos que permitieran elaborar una referencia de conjunto. Pero, si bien es cierto que la Vida del Libertador Simón Bolivar de Felipe Larrazábal gozó de cierto éxito cuando fue publicada en 1865 , la posterior carrera política de su autor terminó por afectar la suerte de la obra. Comprometido en una conspiración dirigida en contra del presidente Antonio Guzmán Blanco, Larrazábal tuvo que exiliarse a Curazao en 1871 y pereció, dos años más tarde, en un naufragio donde se perdió el manuscrito ampliado y corregido de su biografía de Bolívar, así como toda una serie de documentos inéditos que le había agregado.

En cuanto a Juan Vicente González su papel de brillante corifeo del Partido Conservador, y sus posiciones intelectuales contrapuestas a la corriente política imperante en el país desde 1848 , hacían de él un marginal con matices de excentricidad. Sus escritos sobre la historia nacional, en particular su «Biografía de José Felix Ribas», publicada en 1865 en las páginas de la Revista Literaria que acababa de fundar, eran apreciados en función de su valor literario, pero no se les tomaba demasiado en serio.

Se puede entonces concluir que, en un primer momento, este corpus historiográfico venezolano no fue percibido como un aporte a la construcción de una memoria colectiva. Las obras publicadas entre 1830 y el último tercio el siglo XIX no expresaban lo que las élites del momento querían escuchar. Tal como venía presentada en estos textos, la historia de Venezuela, particularmente la historia reciente de la independencia, dejaba demasiadas preguntas sin respuesta $y$, en vez de ofrecer certezas inquebrantables contribuía a sembrar dudas y, más grave aún, a fomentar cuestionamientos.

\section{III}

Paradójicamente, a pesar de todas las críticas -explícitas o implícitas-, este corpus pasaría a ser la fuente principal de referencia para la redacción de los primeros manuales escolares, aunque en una versión truncada que eliminaba cualquier posibi- 
lidad de interpretación crítica. Ritualizada a través del método pedagógico del catecismo - adoptado en todas las aulas del paísel relato podía entonces adquirir la forma canónica de un imaginario colectivo en donde cada episodio contribuía a destacar una sentencia moral o una regla de conducta.

La historia podía transformarse así en certeza absoluta. Cristóbal Colón, kinspirado por el cielon, había sido «escogido por la Providencia para bienestar y gloria del género humano (20). En contraste, los conquistadores del territorio venezolano habían llevado «a todas partes el terror y la desolación» (21) y los caciques indígenas que les resistieron demostraban así su «valor, constancia y patriotismo" (22). La dominación española era rechazada sin vacilación:

Pregunta.- ¿Era bueno el gobierno colonial?

Respuesta.- No, y a él se debía que el país estuviese despoblado, que no hubiese comunicaciones, que el pueblo fuese ignorante y dividido en clases (23).

La independencia pasaba a ser entonces la génesis de una epopeya que ponía en escena a personajes claramente diferenciados: de un lado, los héroes; del otro, los malos. Entre los héroes, Bolívar, sobre todo en los manuales del último cuarto del siglo XIX, adquiría la dimensión de un superhombre "destinado por la Providencia a ser el Libertador de su Patria y de casi toda la América del Sur y a elevar su gloria a la mayor altura que registran los fastos de la historia humana" (24). Los malos, claro está, eran los españoles: "cobardes», "sanguinarios" o "asesinos». Era inapelable el contraste.

Pregunta.- ¿Cómo debemos juzgar entonces la lucha de nuestra independencia?

Respuesta.- Como la lucha titánica que emula y supera a las más heroicas que cuentan los pueblos (25).

(20) Felipe Tejera, Manual de Historia de Venezuela para el uso de las escuelas y colegios, Caracas: Imprenta Federal, 1875. Introducción, Capítulo I, párrafo 5 .

(21) PEOLI, op. cit., pág. 34.

(22) Tejera, [20]. Primera parte, Capítulo VI, párrafo 1.

(23) Manuel María Urbaneja, Catecismo de Historia de Venezuela Caracas: Imprenta de George Corser, 1865, pág. 70.

(24) Antonia ESTELler, Catecismo de Historia de Venezuela. Caracas, Dirección de Instrucción Pública, 1886, pág. 48.

(25) Ibíd., pág. 55. 
La historia podía así construirse con base en una serie de postulados: la sociedad venezolana era una sociedad homogénea, formando una sola kgran familia", unida por su pasado y cuya lucha reciente para obtener la independencia política podía a la vez reflejar esa unión y asegurar una marcha inalterable hacia un radiante porvenir. La complejidad de los problemas planteados por esa independencia desaparecía virtualmente de todos estos textos cuyos límites cronológicos, por lo general, no traspasaban el umbral de la vida republicana, una vez terminada la fase de la lucha armada. Lo que, quizás, era compresible en 1830 o 1850, ya lo era menos medio siglo más tarde. Pero también, como afirmaba un pedagogo mexicano contemporáneo: rel estudio de la minuciosa historia de esas épocas [las más contemporáneas] no es para los niños" (26).

Auxiliar privilegiado de una consolidación efectiva o, mejor dicho, afectiva del patriotismo, la historia enseñada en la escuela consagraba la asimilación de un imaginario. La historia, esa khistoria oficial», pasaria a ser la única verdaderamente patriótica $y$, por ende, aceptable.

Un mismo afán de propaganda, en el sentido literal de la palabra, acompañaría las ceremonias conmemorativas de acción cívica. Un ejemplo entre muchos: el 14 de octubre de 1883, Jesús María Espíndola se dirigía a la población de La Asunción, en la isla de Margarita, con motivo de la inauguración de una plaza dedicada al prócer local de la independencia Francisco Esteban Gómez. Su evocación del cuadro histórico de los tres siglos de colonia era particularmente elocuente:

Fue un tiempo, señores, en que la América gemía bajo el peso de la más horrible servidumbre. Toda la vasta extensión del continente era una ergástula donde no se oía sino el chasquido del látigo del rudo mayoral, el grito de agonía de una raza desgraciada y el ruido siniestro de las cadenas del esclavo (27).

La independencia, por lo tanto, asumía la forma de una transformación radical:

El esclavo se hizo héroe, el siervo ciudadano, soldado el niño

(26) Epitacio de los Ríos, Compendio de la Historia de México, (1852), pág. 231, citado por Josefina Zoraida VÁzouEz, Nacionalismo y Educación en México, México. El Colegio de México, 1970, pág. 41.

(27) Jesús María Espíndola, Discurso de orden [...] en la Plaza "Gómez" de La Asunción. La Asunción, s.e., 1883, pág. 2. 
adolescente [...] trabóse la lucha encarnizada y tenaz, y fue teatro portentoso de homéricas hazañas esta tierra gloriosa (28). que:

En cuanto al prócer objeto del homenaje, era nada menos intrépido y esforzado como Aníbal, como Leónidas sagaz y estratégico, inmaculado como Arístides, padre y protector del pueblo como el primero de los gracos (29).

Aún quienes no supieran con precisión el significado de la palabra kergástulaw, o no tuviesen la menor idea de quienes eran Aníbal, Leónidas o el primero de los Gracos, podían quedar debidamente edificados.

La exaltación de todas estas hazañas servía, además, el propósito de levantar una autoestima, a nivel tanto local como nacional. Cada región debía de tener su prócer y demostrar así haber contribuído a la formación de la patria común. Por otra parte, los conflictos o las tensiones del momento podian obviarse ante la referencia reiterada hacia un pasado idealizado como una fuente inagotable de redención para los pecados del presente. De ahi, y por ejemplo, que el discurso pronunciado en el cementerio de Caracas, durante la ceremonia de exequias del anciano expresidente Carlos Soublette en febrero de 1870, hiciera particular hincapié de que:

Sólo a la verdadera virtud, a la santa honradez que baja al sepulcro ceñida con la blanca y humilde toga de la pobreza, es dado arrancar estos honores póstumos ... He aquí joh juventud! lo único digno de emulación y de la envidia de las almas que aspiran a figurar honrosamente en los anales de la patria. Venezuela ha probado en ocasiones tan memorables como la de hoy que no será nunca una gran colonia fenicia como Cartago, compuesta de mercaderes descorazonados, ni una Roma como la de Sexto Tarquino y Tulia (30).

Indudablemente que el logro más acabado en cuanto a esta glorificación del héroe por medio del discurso y de la conmemoración ceremonial vendría a ser el del culto a la figura de Simón

(28) Ídem, págs. 2-3.

(29) Ídem, Ibídem.

(30) Juan Bautista Querales, Comp. Soublette y la prensa de su época, Caracas, Academia Nacional de la Historia, 1979, págs. 608-609. 
Bolívar, virtualmente convertida en razón de ser de la nacionalidad. Esta conversión no fue inmediata, sino el resultado de una evolución a lo largo del siglo XIX. La repatriación de los restos del Libertador desde Santa Marta a Caracas, en 1842, constituyó una primera etapa que desembocaría, con los actos del centenario de su nacimiento en 1883, a una consagración definitiva.

\section{IV}

Más allá de la recuperación de una memoria colectiva, el discurso historiográfico venezolano del siglo XIX se encargaría de conformar los elementos de un imaginario. Mientras se recusaban las orientaciones propuestas por el corpus de obras sobre la historia nacional, algunos elementos de ese corpus serían adoptados por la crítica. En particular aquellos que tenían que ver con los modelos de referencia histórica de los cuales constantemente se sacaban a relucir renovadas correlaciones.

El primero de esos modelos era el de la Antigüedad clásica, aunque se trataba, claro, de una Antigüedad revisada y corregida con la finalidad de satisfacer unos propósitos específicos. Para poder así cumplir con su misión edificante, la historia evocaría el pasado nacional en términos de una mítica edad de oro, en donde la virtud y la sabiduría podían reinar de una manera soberana, mientras adoptaban el lenguaje de la epopeya. De ahí que, para Juan Vicente González y todos sus epígonos de plaza pública, Bolívar sería a la vez el Aquiles o el Ulises de una nueva versión del poema homérico. Sus compañeros podían ser entonces, según lo ameritase el caso, unos Ajax, unos Néstores o las modernas reencarnaciones de "Fabio [Cunctator]». El propio González justificaría esta posición, al escribir que

las épocas clásicas de Grecia y de Roma son el objeto de la constante emulación de todos los siglos (31).

Otro objeto de emulación: la Revolución francesa, de la cual se deploraban los excesos sanguinarios, pero cuyo ejemplo permitía asimilar las guerras y todo el proceso de la Independencia a una reivindicación "popular» en favor del Estado-Nación. Los debates del Congreso Constituyente de 1811, descritos por Juan

(31) Juan Vicente González, "Al redactor de El Monitor". El Heraldo, Caracas, $n^{2} 33,23$ de julio de 1859 . 
Vicente González, se convertían así en los de la Convención y los oradores de la asamblea criolla parecían ser las reencarnaciones de sus antecesores franceses de 1793.

Un hombre se levanta y usurpa la palabra; pero no es un hombre ese cíclope, con dos agujeros por ojos, afeado por la viruela, de cabeza enorme cubierta de erizadas cerdas, de ideas febriles servidas por una voz de trueno (32).

No se trata aquí de Danton, sino de Felipe Fermín Paúl - Coto Paúl-, uno de los tribunos de la «Sociedad Patriótica» de 1811.

Juan Vicente González, por otra parte, insistía sobre el hecho que las cualidades intrínsecas de los personajes de la historia se reflejaban imborrablemente en sus fisonomías. Así Bolivar tendría:

Ojos azules y color blanco, que ennegrecerán los rayos de la guerra, músculos de acero, mirada soberbia y terrible, las formas elegantes y varoniles del dios de las batallas (33).

En cambio, Francisco Rosete, uno de los jefes realistas españoles, sería:

Rechoncho, de una blancura sucia, de andar convulsivo, coronábale una calva innoble; dos ojos desiguales y saltados acechaban desde sus sienes, y arrojaba por los abismos de su pestilente boca amenazas y blasfemias (34).

No puede haber patria sin independencia o sin libertad, pero tampoco podía haberla sin héroes. Estos últimos tenían el privilegio de poder encarnar la nación a los ojos del ciudadano y, al mismo tiempo, de proporcionar un ejemplo a seguir. En efecto la patria se confundía con el régimen republicano que salió de su seno y que debía ser un modelo de probidad y de virtud cívica.

Auxiliar privilegiado de la construcción nacional, la historia serviría también para consolidar el poder de quienes se habían preocupado por definir cuáles deben ser sus parámetros. Al adoptar de antemano los arquetipos que proporcionaban las llamadas «nacionalidades satisfechas», según la expresión de Ruggiero Ro-

(32) Juan Vicente González, "Biografía de José Félix Ribas" en Pensamiento Político Venezolano del siglo XIX, Caracas, Publicaciones del Congreso de la República, 1983, Tomo III, págs. 110-111.

(33) Idem, pág. 109.

(34) Ídem, págs. 192-193. 
mano (35), era posible entonces idealizar unas referencias mientras se adaptaban a un nuevo contexto. Que ese contexto fuese el de una "nacionalidad frustrada" - siempre de acuerdo con la expresión utilizada por Romano (36) - favorecía la construcción de un imaginario que se encargaría, con el tiempo, de legitimar un discurso mediante el cual los procesos de una historia real lograban confundirse con los mitos de una historia deseada.

(35) Ruggiero Romano, “Algunas consideraciones alrededor de Nación, Estado (y Libertad) en Europa y Ámérica Centro Meridional", en Antonio ANNINO, et al. América Latina; del Estado Colonial al Estado Nación, 1750-1940, Turin, Franco Angeli, 1987, tomo I, pág. 4.

(36) Ídem, Ibídem. 